\title{
Regulation data for the horizontal jump of children and adolescents
}

Rossana Gomez-Campos (1), Ruben Vidal-Espinoza (2), Luis Felipe Castelli Correia de Campos (3), Cynthia Lee Andruske (4), Jose Sulla-Torres (5), Camilo Urra-Albornoz (6), Wilbert Cossio-Bolaños (7), Fernando Alvear-Vasquez (8), Jorge Mendez-Cornejo (1), Marco Cossio-Bolaños (1)

(1) Universidad Católica del Maule, Talca, Chile; (2) Universidad Católica Silva Henriquez, Santiago, Chile; (3) Universidad del Bío Bío, Chillán, Chile; (4) Centro de Investigación, CINEMAROS, Arequipa, Perú; (5) Universidad Nacional de San Agustín de Arequipa, Arequipa, Perú; (6) Escuela de Kinesiología, Facultad de Salud, Universidad Santo Tomás, Chile; (7) Universidad Privada San Juan Bautista, Lima, Perú; (8) Universidad de Valencia, Valencia, España.

This article is distributed under the terms of the Creative Commons Attribution Noncommercial License (CC BY-NC 4.0) which permits any noncommercial use, distribution, and reproduction in any medium, provided the original author(s) and source are credited.

\begin{abstract}
The Horizontal Jump (HJ) is a daily tool that could be used to categorize the level of muscle fitness performance of the lower limbs. The goal was to compare the muscle fitness with those of international studies and to propose percentiles to assess the HJ performance of children and adolescents. A cross-sectional study was conducted. A total number of 3023 children and adolescents between the ages of 6.0 to 17.9 were studied. Weight, height, waist circumference (WC), and lower limb muscle fitness were evaluated. The student HJ performance values in Chile were inferior when compared to HJ performance in Brazil, Poland and Europe. For the Greek study, differences occurred only from age 6 to 15 years old. In comparison to Colombia, students showed better muscle fitness performance. These differences appeared in childhood and lasted until the beginning of adolescence. Percentiles were created to assess the lower limb fitness being an easy tool to be used and applied to classify lower limb strength.
\end{abstract}

Key Words: horizontal jump; child health; regulations; health promotion.

Muscle fitness has several dimensions. These may be assessed in children and adolescents (for example, maximum isometric strength, muscle endurance, and explosive strength). ${ }^{1}$ In fact, horizontal jump (HJ) and the vertical jump are from the classical batteries of field tests commonly used to assess the physical fitness of students through explosive muscle strength of the lower part of the body. ${ }^{2,3}$ The HJ is a combination of movements that not only depend upon properties of the muscles, but also multiple joints used in the motor system. This involves taking off and landing with both feet to attain the maximum horizontal distance. ${ }^{1}$ Basically, this test is proposed as a general indicator of muscle fitness in children and adolescents. ${ }^{4}$ Muscle fitness is an important health indicator that is inversely and independently associated with muscle endurance, metabolic risk, inflammatory proteins, and body adiposity during childhood and adolescence. ${ }^{5-7}$ It is an essential component of performance in sports. Therefore, it plays an important role in the selection of school athletes. ${ }^{8}$ The
$\mathrm{HJ}$ test is low cost, has simple equipment to use, it is easy to administer to a large number of individuals simultaneously, ${ }^{9}$ and has high validity and reliability in children and adolescents. ${ }^{4}$ As a result, due to these characteristics, it is necessary to include the $\mathrm{HJ}$ as an important test in the educational system for assessing health and determining sport performance in students. In this sense, researchers in a number of studies in South America, ${ }^{9-11}$ and throughout the world, ${ }^{12-14}$ have proposed references to assess $\mathrm{HJ}$ performance for children and adolescents. Thus, its use and application in Chile may reflect discrepancies, limiting its use due to geographical, social, and cultural differences between countries. ${ }^{7}$ In addition, muscle fitness may vary between individuals, especially during adolescence, to repeat the exercise might be important to detect changes produced in biological maturation. ${ }^{15}$ In the absence of studies that address muscle fitness and especially to assess the performance of horizontal jump in school children and adolescents, this study proposed two objectives. The first was to compare the muscle fitness, using the HJ, between 
students of Chile Maule Region and those of international studies. The second was to propose percentiles for assessing $\mathrm{HJ}$ of children and adolescents from the Maule Region (Chile).

\section{Materials and Methods}

This descriptive cross-sectional study was carried out in 12 schools in the Maule Region (Chile). Maule, located in the central valley, is the seventh region of Chile. Its capital city is Talca. Agriculture is the primary industry of the region.

\section{Sample size}

The sample population was composed of 29,500 (17,410 males and 12,100 females) children and adolescents from the public education system. The research sample was selected probabilistically (CI 95\%). The appropriate sample size was 3061 (10.3\%) [1930 (6.5\%) males and 1131 (3.8\%) females]. Students of both sexes, ages 6.0 to 17.9 years old, were included in the study. Students with physical and/or motor problems that impeded performing or assessing the horizontal jump or did not complete the physical tests were excluded from participating (120 males and 170 females).

\section{Ethical considerations}

The study was carried out according to the Declaration of Helsinki World Medical Association for Human Subjects. ${ }^{16}$ The research was also approved by the Ethics Committee from the Universidad (grant number-2413). All sample subjects for this study were informed about its objectives. Parents and/or guardians and students all provided signed informed consent for students to participate in the research.

\section{Procedures}

Anthropometric variables and the horizontal jump were assessed at the schools. School administrators from each educational institution provided birth certificates to collect information for the assessment date. Data was collected from April to November 2017. Anthropometric variables for body weight, height, and waist circumference (WC) were collected according to the standard procedures described by Ross-Marfell-Jones. ${ }^{17}$ All variables were measured while the students were barefoot and dressed with minimum clothing. Body weight was collected using an electronic portable scale (Tanita Inner Scan BC 532, Tokyo, Japan) with an accuracy of close to $0.10 \mathrm{~kg}$. Using the Frankfurt Plane, height was measured with a portable stadiometer (Seca 213, Hamburg, Germany) with a precision of $0.1 \mathrm{~cm}$. WC was assessed midway from the lower ribs and the upper part of the iliac crest. Measurements were taken with an anthropometric metal tape, Seca brand, with an accuracy of $0.1 \mathrm{~cm}$. Body Mass Index (BMI) was calculated using the formula: $\mathrm{BMI}=$ weight $(\mathrm{kg}) /$ height $^{2}(\mathrm{~m})$. The horizontal jump (cm) for the muscle fitness test of the lower limbs was evaluated after a 10 minute warm up period. Students were dressed in tennis shoes, shorts, and a T-shirt to perform the test. Assessments were carried out based on the recommendations of Castro-Piñero et al. ${ }^{9}$ A $3 \mathrm{~m}$ metal tape measure with an accuracy of $0.1 \mathrm{~cm}$ was used to measure the distance of the horizontal jump. With feet together, the student performed a forward movement with as much momentum as possible in order to go as far as possible from the original starting line. Students performed three attempts. Then, the best distance was recorded. Afterwards, the results were compared. The levels of muscle fitness from the horizontal jump of the Chilean students were compared with the references from Brazil, ${ }^{11}$ Columbia, ${ }^{9}$ Poland, ${ }^{12}$ Greece, ${ }^{18}$ and the European 30 country multi-centric study. ${ }^{14}$ All those studies reported normal distribution in their data.

\section{Statistical analysis}

Data normalization was carried out using Kolmoronov Smirnov method. Descriptive statistical analysis of the mean, standard deviation (SD), and ranges were performed. Comparisons between both sexes were carried out by using the t-test for independent samples. The fraction $100 \mathrm{log}$ (reference percentile/centile calculated) was used to make comparisons between the studies. P50 was used for all cases. All calculations were performed with SPSS 18.0. For all comparisons, $\mathrm{p}<0.05$ was adopted. The LMS method was used to create the percentiles. This method was based on three smoothed curves [L(t) Box-Cox transformation, M(t) median, and $\mathrm{S}(\mathrm{t})$ coefficient of variation]. ${ }^{19}$ Percentiles P50, P90, P95, and P97 were calculated for absolute height for both sexes. LMS Chart Maker software version 2.320 generated the curves.

\section{Results}

Mean \pm SD, anthropometric variables, and HJ performance values for the children and adolescents from Maule (Chile) are presented in Table 1. No significant differences occurred in weight and WC from age 6.0 to 14.9 years old. However, from 15.0 years old to 17.9 , males presented higher values than the females $(\mathrm{p}<0.05)$. Height values were similar until 13 years old. From age 14.0 to 17.9 years, males were taller than the females $(p<0.05)$. For the HJ, for all age ranges, males had significantly higher values than the females $(p<0.05)$. With regard to BMI, at age 17 years old, males presented higher values than females $(\mathrm{p}<0.05)$. P50 was used to compare the differences in the HJ performance between the Maule students studied and the international references. Table 2 illustrates these differences. The Maule students presented lower values than those of students from Brazil, ${ }^{11}$ Poland, ${ }^{12}$ and the European multicentric study in all age ranges and in both sexes. ${ }^{14}$ These lower values were from -2.1 to $-8.2 \mathrm{~cm}$ for males and from 0.3 to $17.9 \mathrm{~cm}$ for females. For the Greek study, ${ }^{20}$ differences occurred from age 6 to15 years old (-7.5 to $1.0 \mathrm{~cm}$ for males and -8.6 .1 to $-0.3 \mathrm{~cm}$ for females). Then, at the age of 16 and 17, the females of Maule showed 
Horizontal jump of Chile children and adolescents

Eur J Transl Myol 31 (2): 9461, 2021 doi: 10.4081/ejtm.2021.9461

\begin{tabular}{|c|c|c|c|c|c|c|c|c|c|c|c|}
\hline \multirow{2}{*}{ Age (years) } & & \multicolumn{2}{|c|}{ Weight (kg) } & \multicolumn{2}{|c|}{ Height (cm) } & \multicolumn{2}{|c|}{ BMI $\left(\mathbf{k g} / \mathbf{m}^{2}\right)$} & \multicolumn{2}{|c|}{ WC (cm) } & \multicolumn{2}{|c|}{ HJ (cm) } \\
\hline & $\mathrm{N}$ & $\mathrm{X}$ & SD & $\mathrm{X}$ & $\mathrm{SD}$ & $\mathrm{X}$ & SD & $\mathrm{X}$ & SD & $\mathrm{X}$ & SD \\
\hline & \multicolumn{11}{|c|}{ Males } \\
\hline $6.0-6.9$ & 60 & 26.2 & 5.3 & 120.3 & 5.6 & 18.0 & 2.7 & 59.1 & 5.9 & 90.7 & 18.8 \\
\hline 7.0-7.9 & 116 & 29.1 & 8.6 & 125.6 & 8.9 & 18.2 & 2.6 & 61.2 & 7.8 & 103.8 & 20.0 \\
\hline 8.0-8.9 & 156 & 30.7 & 6.1 & 129.2 & 5.5 & 18.3 & 2.9 & 63.1 & 8.0 & 101.5 & 20.5 \\
\hline $9.0-9.9$ & 108 & 39.3 & 8.1 & 136.5 & 6.5 & 21.0 & 3.5 & 69.9 & 9.8 & 108.2 & 18.8 \\
\hline $10.0-10.9$ & 182 & 40.5 & 10.0 & 141.0 & 6.7 & 20.2 & 3.9 & 71.6 & 10.8 & 121.7 & 21.4 \\
\hline $11.0-11.9$ & 178 & 44.1 & 9.0 & 147.5 & 7.6 & 20.2 & 3.1 & 72.0 & 10.0 & 132.5 & 19.5 \\
\hline $12.0-12.9$ & 220 & 50.6 & 10.9 & 152.9 & 8.3 & 21.6 & 4.1 & 73.4 & 9.9 & 138.4 & 22.4 \\
\hline 13.0-13.9 & 157 & 53.1 & 12.0 & 158.0 & 8.8 & 21.1 & 3.8 & 74.9 & 8.7 & 154.0 & 29.4 \\
\hline $14.0-14.9$ & 196 & 60.6 & 13.1 & 163.7 & 8.2 & 22.5 & 4.0 & 75.8 & 11.0 & 160.1 & 31.6 \\
\hline $15.0-15.9$ & 231 & 67.1 & 13.1 & 170.1 & 7.0 & 23.2 & 4.1 & 78.8 & 10.6 & 177.2 & 29.2 \\
\hline $16.0-16.9$ & 175 & 68.5 & 13.0 & 171.3 & 5.1 & 23.3 & 4.2 & 77.4 & 10.2 & 181.4 & 27.2 \\
\hline $17.0-17.9$ & 151 & 68.8 & 14.3 & 169.8 & 6.6 & 24.4 & 5.1 & 77.3 & 10.1 & 192.6 & 27.3 \\
\hline \multirow[t]{2}{*}{ Total } & 1928 & 51.0 & 17.9 & 152.3 & 17.6 & 21.3 & 4.2 & 72.2 & 11.2 & 144.3 & 39.6 \\
\hline & \multicolumn{11}{|c|}{ Females } \\
\hline $6.0-6.9$ & 89 & 25.5 & 5.2 & 119.2 & 5.4 & 17.8 & 2.8 & 61.3 & 7.7 & $79.0^{*}$ & 14.9 \\
\hline $7.0-7.9$ & 129 & 26.9 & 5.3 & 124.3 & 5.3 & 17.4 & 2.9 & 61.6 & 7.6 & $82.1^{*}$ & 21.5 \\
\hline $8.0-8.9$ & 113 & 29.9 & 5.7 & 128.6 & 4.6 & 18.1 & 2.9 & 61.8 & 7.6 & $85.9 *$ & 23.1 \\
\hline $9.0-9.9$ & 87 & 35.8 & 7.2 & 133.3 & 6.2 & 20.1 & 3.4 & 70.5 & 9.4 & $104.6^{*}$ & 15.6 \\
\hline 10.0-10.9 & 99 & 40.8 & 8.5 & 141.3 & 6.8 & 20.4 & 3.9 & 66.9 & 9.4 & $113.6^{*}$ & 20.1 \\
\hline $11.0-11.9$ & 114 & 48.0 & 12.6 & 147.3 & 8.7 & 21.9 & 4.5 & 69.1 & 11.5 & $117.0^{*}$ & 16.8 \\
\hline $12.0-12.9$ & 124 & 49.2 & 9.5 & 153.6 & 7.0 & 20.8 & 3.5 & 70.7 & 8.2 & $121.8^{*}$ & 18.7 \\
\hline 13.0-13.9 & 86 & 55.0 & 10.0 & 157.2 & 7.7 & 22.2 & 3.6 & 73.5 & 8.2 & $126.6^{*}$ & 20.5 \\
\hline $14.0-14.9$ & 79 & 58.6 & 9.1 & $158.6^{*}$ & 7.4 & 24.3 & 4.6 & 73.0 & 8.5 & $131.9^{*}$ & 24.0 \\
\hline 15.0-15.9 & 81 & $61.2^{*}$ & 10.7 & $160.3^{*}$ & 6.7 & 23.9 & 4.5 & $73.7^{*}$ & 8.7 & $133.4^{*}$ & 31.2 \\
\hline 16.0-16.9 & 80 & $59.6^{*}$ & 9.1 & $160.8^{*}$ & 6.0 & 23.0 & 3.3 & $74.0^{*}$ & 7.7 & $140.1^{*}$ & 25.3 \\
\hline $17.0-17.9$ & 50 & $61.8^{*}$ & 9.8 & $165.2^{*}$ & 9.2 & $22.1^{*}$ & 2.5 & $75.1^{*}$ & 6.7 & $169.3^{*}$ & 41.8 \\
\hline Total & 1095 & 44.5 & 15.6 & 144.2 & 16.4 & 20.7 & 4.3 & 68.4 & 9.9 & 108.3 & 38.4 \\
\hline
\end{tabular}

X: Average, SD: Standard deviation, BMI: Body Mass Index, WC: Waist circumference, HJ: Horizontal jump, *: p<0.05.

better performance in the $\mathrm{HJ}$ (2.1 to $5.3 \mathrm{~cm})$. In relation to the Colombian study, ${ }^{9}$ the students from the Maule Region performed better (for male: 0.7 to $7.1 \mathrm{~cm}$ and for females: 2.5 to $10.4 \mathrm{~cm}$ ). Comparisons between $\mathrm{HJ}$ from international studies (p50) are shown in Figure 1. Values increased as age advanced until ages 14 to 15 years old. During the later ages, minor differences occurred between the Chile students and students of the international studies, except for the Colombian study, which performed poorly in relation to the other studies. ${ }^{9}$ Table 3 illustrates the percentiles for $\mathrm{HJ}$ by age and sex (P3, P5, P10, P15, P25, P50, P75, P85, P90, P95, and P97). For both sexes, the values increased as age advanced. 
Horizontal jump of Chile children and adolescents

Eur J Transl Myol 31 (2): 9461, 2021 doi: 10.4081/ejtm.2021.9461

Table 2. Differences between the HJ of Maule and those of the international references (percentile 50)

\begin{tabular}{|c|c|c|c|c|c|c|c|c|c|c|}
\hline \multirow[t]{2}{*}{ Age (years) } & \multicolumn{2}{|c|}{ Brazil } & \multicolumn{2}{|c|}{ Colombia } & \multicolumn{2}{|c|}{ Greece } & \multicolumn{2}{|c|}{ Poland } & \multicolumn{2}{|c|}{ Multicentric } \\
\hline & M & $\mathrm{F}$ & $\mathrm{M}$ & $\mathrm{F}$ & $\mathrm{M}$ & $\mathrm{F}$ & $\mathrm{M}$ & $\mathrm{F}$ & $\mathrm{M}$ & $\mathrm{F}$ \\
\hline $6.0-6.9$ & -5.2 & -9.2 & -- & -- & -5.0 & -8.5 & -- & -- & -- & -- \\
\hline $7.0-7.9$ & -6.2 & -17.9 & -- & -- & -6.2 & -8.6 & -5.3 & -9.6 & -- & -- \\
\hline $8.0-8.9$ & -7.1 & -12.5 & -- & -- & -7.5 & --8.2 & -7.0 & -8.3 & -- & -- \\
\hline $9.0-9.9$ & $-7,0$ & $-7,6$ & 0.7 & 2.5 & -7.3 & -7.2 & -7.7 & -7.4 & -8.2 & -- \\
\hline $10,0-10,9$ & -6.2 & -4.8 & 0.8 & 3.5 & -6.3 & -6.0 & -7.4 & -7.6 & -7.4 & -5.0 \\
\hline $11.0-11.9$ & -5.5 & -3.9 & 2.5 & 3.8 & -5.2 & -5.8 & -6.6 & -7.6 & -6.6 & -5.5 \\
\hline $12.0-12.9$ & -5.1 & -3.8 & 5.0 & 4.2 & -4.3 & -4.9 & -6.3 & -8.3 & -5.6 & -6.3 \\
\hline $13.0-13.9$ & -4.6 & -3.7 & 4.3 & 4.1 & -3.1 & -3.8 & -6.5 & -8.9 & -4.4 & -6.9 \\
\hline $14.0-14.9$ & -4.3 & -3.7 & 4.8 & 5.3 & -2.0 & -2.3 & -6.7 & -9.1 & -4.0 & -6.4 \\
\hline $15.0-15.9$ & -3.8 & -3.6 & 4.7 & 7.0 & -0.9 & -0.3 & -6.6 & -8.0 & -3.9 & -5.3 \\
\hline $16.0-16.9$ & -3.0 & -2.4 & 5.6 & 8.7 & -0.1 & 2.2 & -5.7 & -5.3 & -3.4 & -3.2 \\
\hline $17.0-17.9$ & -2.1 & -0.3 & 7.1 & 10.6 & 0.9 & 5.5 & -4.5 & -1.9 & -2.5 & -0.6 \\
\hline
\end{tabular}

X: Average, SD: Standard deviation, BMI: Body Mass Index, WC: Waist circumference, HJ: Horizontal jump, *: $p<0.05$.

\section{Discussion}

The results of this study showed differences in the HJ performance when compared with those of the international studies. In general, the students from the Maule displayed lower values during childhood and adolescence when compared to studies carried out in Brazil, ${ }^{11}$ Poland, ${ }^{12}$ and other 30 European countries, multi-centries study. ${ }^{14}$ However, in comparison to the Greek studies, ${ }^{18,20}$ the Maule students HJ performance was lower until age 14, but the values began to be more similar as age advanced. Furthermore, the present research determined that both sexes of the students from the Maule presented higher values when compared to the Colombian student values, ${ }^{9}$ especially during adolescence. This demonstrated that at advanced ages
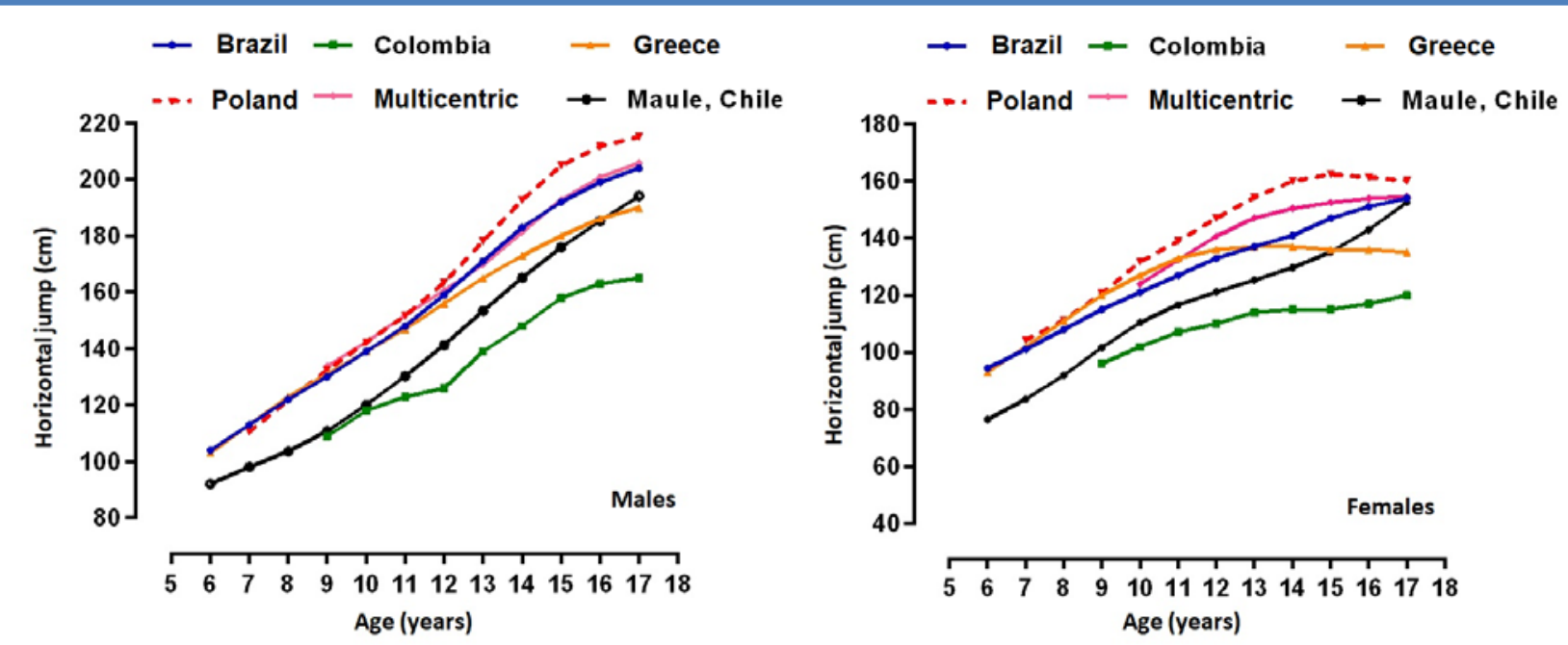

Fig 1. HJ performance of students from international studies and the students from the Maule (Chile). 
(17.0 - 17.9 years old), the Maule students approached the medians achieved by students of the international studies (200 cm for males and $160 \mathrm{~cm}$ for females). These results are consistent with various studies carried out at diverse elevations over the see level. Some researchers have reported that the differences in muscle fitness are primarily due to genetic ${ }^{4,21,22}$ and environmental factors. Within environmental factors, differences have been reported due to living areas (urban and rural, ${ }^{23}$ training levels, ${ }^{24}$ secular tendencies, ${ }^{25}$ among other factors such performing physical activity, ${ }^{26}$ and lifestyle. ${ }^{27}$ In fact, Chile in recent years has been decreasing muscle fitness performance in children and adolescents and at the same time overweight and obesity has been increasing, ${ }^{7}$ which could be determined by low levels of physical activity and sedentary lifestyles. Consequently, the differences found between under developed and developed countries in different parts of the world help to describe the important role of the geographic variability. Furthermore, it seems reasonable to suggest that body weight plays an even more relevant role in the execution of the HJ test. Thus, in general, students with lower levels of physical activity, not completing the 60 minute minimum daily requirement of moderate to vigorous physical

Table 3. Percentile distributions by age and sex for HJ for children and adolescents from Maule (Chile).

\begin{tabular}{|c|c|c|c|c|c|c|c|c|c|c|c|c|c|c|}
\hline Age & $\mathbf{L}$ & $\mathbf{M}$ & $\mathrm{s}$ & P3 & P5 & P10 & P15 & P25 & P50 & P75 & P85 & P90 & P95 & P97 \\
\hline \multicolumn{15}{|c|}{ Males } \\
\hline $6.0-6.9$ & 0.41 & 91.96 & 0.20 & 60.5 & 64.0 & 69.7 & 73.6 & 79.8 & 92.0 & 105.2 & 112.7 & 118.0 & 126.1 & 131.5 \\
\hline $7.0-7.9$ & 0.55 & 97.98 & 0.20 & 64.7 & 68.5 & 74.6 & 78.8 & 85.3 & 98.0 & 111.4 & 119.0 & 124.2 & 132.1 & 137.4 \\
\hline $8.0-8.9$ & 0.70 & 103.58 & 0.19 & 68.6 & 72.7 & 79.3 & 83.8 & 90.5 & 103.6 & 117.2 & 124.6 & 129.8 & 137.5 & 142.6 \\
\hline $9.0-9.9$ & 0.82 & 110.77 & 0.18 & 73.7 & 78.2 & 85.2 & 90.0 & 97.2 & 110.8 & 124.6 & 132.2 & 137.4 & 145.1 & 150.1 \\
\hline $10.0-10.9$ & 0.94 & 120.07 & 0.18 & 80.4 & 85.3 & 92.9 & 98.1 & 105.7 & 120.1 & 134.5 & 142.3 & 147.6 & 155.5 & 160.6 \\
\hline $11.0-11.9$ & 1.05 & 130.31 & 0.17 & 87.5 & 92.9 & 101.2 & 106.8 & 115.1 & 130.3 & 145.5 & 153.6 & 159.0 & 167.1 & 172.4 \\
\hline $12.0-12.9$ & 1.19 & 141.29 & 0.17 & 94.6 & 100.7 & 109.9 & 116.0 & 125.0 & 141.3 & 157.3 & 165.7 & 171.4 & 179.7 & 185.1 \\
\hline 13.0-13.9 & 1.36 & 153.36 & 0.17 & 102.1 & 108.9 & 119.2 & 126.0 & 135.8 & 153.4 & 170.2 & 179.0 & 184.9 & 193.5 & 199.0 \\
\hline $14.0-14.9$ & 1.52 & 165.14 & 0.16 & 109.6 & 117.3 & 128.7 & 136.0 & 146.5 & 165.1 & 182.7 & 191.8 & 197.8 & 206.5 & 212.1 \\
\hline $15.0-15.9$ & 1.69 & 175.97 & 0.16 & 117.3 & 125.7 & 137.9 & 145.7 & 156.7 & 176.0 & 193.9 & 203.0 & 209.0 & 217.8 & 223.3 \\
\hline $16.0-16.9$ & 1.87 & 185.26 & 0.15 & 124.8 & 133.7 & 146.4 & 154.5 & 165.8 & 185.3 & 203.1 & 212.1 & 218.0 & 226.6 & 232.0 \\
\hline $17.0-17.9$ & 2.06 & 194.10 & 0.14 & 132.5 & 141.8 & 155.0 & 163.3 & 174.7 & 194.1 & 211.6 & 220.4 & 226.2 & 234.4 & 239.6 \\
\hline \multicolumn{15}{|c|}{ Females } \\
\hline $6.0-6.9$ & 1.15 & 76.39 & 0.24 & 39.7 & 44.5 & 51.8 & 56.6 & 63.6 & 76.4 & 88.8 & 95.4 & 99.8 & 106.3 & 110.5 \\
\hline $7.0-7.9$ & 1.15 & 83.58 & 0.23 & 46.4 & 51.2 & 58.6 & 63.5 & 70.6 & 83.6 & 96.3 & 103.0 & 107.5 & 114.1 & 118.4 \\
\hline $8.0-8.9$ & 1.14 & 91.87 & 0.21 & 54.4 & 59.2 & 66.6 & 71.5 & 78.7 & 91.9 & 104.8 & 111.6 & 116.2 & 122.9 & 127.3 \\
\hline $9.0-9.9$ & 1.07 & 101.7 & 0.19 & 64.4 & 69.1 & 76.4 & 81.3 & 88.4 & 101.7 & 114.8 & 121.8 & 126.5 & 133.5 & 138.0 \\
\hline $10.0-10.9$ & 0.96 & 110.51 & 0.18 & 73.9 & 78.5 & 85.5 & 90.3 & 97.3 & 110.5 & 123.8 & 130.9 & 135.8 & 143.0 & 147.6 \\
\hline $11.0-11.9$ & 0.81 & 116.67 & 0.17 & 81.0 & 85.3 & 92.1 & 96.7 & 103.6 & 116.7 & 130.0 & 137.3 & 142.3 & 149.7 & 154.6 \\
\hline $12.0-12.9$ & 0.64 & 121.24 & 0.17 & 85.7 & 89.9 & 96.5 & 101.1 & 108.0 & 121.2 & 135.0 & 142.7 & 147.9 & 155.8 & 161.0 \\
\hline $13.0-13.9$ & 0.49 & 125.31 & 0.17 & 88.5 & 92.8 & 99.5 & 104.2 & 111.4 & 125.3 & 140.1 & 148.3 & 154.1 & 162.8 & 168.6 \\
\hline $14.0-14.9$ & 0.37 & 129.62 & 0.18 & 90.3 & 94.8 & 101.9 & 106.9 & 114.5 & 129.6 & 145.9 & 155.2 & 161.7 & 171.6 & 178.2 \\
\hline $15.0-15.9$ & 0.30 & 135.13 & 0.19 & 92.0 & 96.8 & 104.5 & 109.9 & 118.3 & 135.1 & 153.5 & 164.1 & 171.6 & 183.0 & 190.8 \\
\hline $16.0-16.9$ & 0.30 & 142.91 & 0.21 & 94.1 & 99.5 & 108.1 & 114.3 & 123.8 & 142.9 & 164.0 & 176.2 & 184.9 & 198.2 & 207.2 \\
\hline $17.0-17.9$ & 0.34 & 152.61 & 0.23 & 96.5 & 102.7 & 112.6 & 119.6 & 130.5 & 152.6 & 177.0 & 191.2 & 201.1 & 216.5 & 226.9 \\
\hline
\end{tabular}

M: median; L: Box-Cox transformation; S: coefficient of variation, P: Percentile. 
exercises, ${ }^{28}$ may have difficulty achieving acceptable muscle fitness values for the lower limbs. ${ }^{7}$

Under this point of view, despite not having controlled for the patterns of physical activity of the students studied, the researchers of the present work found that the performance level of the $\mathrm{HJ}$ when compared with student HJ of the international studies was acceptable. Actually the Maule students participated once a week to a physical education classes performing activities related to body training, games, and sports. Many of these activities are frequently utilized in epidemiological studies and educational contexts, ${ }^{5,29}$ as a testimony for improving health and sports performance. As a result, after discovering differences in the HJ performance among students from different parts of the world, authors of the present study developed percentiles to assess the lower limbs muscle fitness from childhood to adolescence. To rank the students with low, moderate, and high levels of the lower limbs muscle fitness might very important either in the educational setting or in the sport context. This information is relevant for professionals working in educational environments (schools), athletics (identification of talent), and health (sports and fitness clubs). ${ }^{30}$ Researchers from various international studies have suggested classifying in quintiles as a normative framework for categorizing general physical fitness performance. ${ }^{31,32}$ The latter ranks individuals below p20 to be very low, between p20 and p40 low, from p40 to p60 moderate, from p60 to p80 high, and more than >p80 good/very high. Other studies have reported lower values up to $<$ p15 as low level warning signs while interpreting p15 to p80 as adequate, and above >p85 as a high level of fitness. ${ }^{11,33}$ The cut-off points selected for this study coincide with those proposed by researchers from previous studies ( $\mathrm{p}<15$, p15 to $\mathrm{p} 85$, and $>\mathrm{p} 85$ ). However, according to Dobosz et al., ${ }^{12}$ regardless of the uses and applications, children and/or adolescents classified above p90 or p97 need to be considered as talented, especially for those sports where this component is relevant. Those classified below p15, need to be informed or included into physical fitness programs. Given that risk groups exist among children, adolescents, young, and adults, the World Health Organization encourages research groups to find new tools and more precise evaluations of health, encouraging children to actively participate in lifestyle education at very early ages. ${ }^{34,35}$ Thus, the percentiles proposed in this research study could be used as a daily tool to categorize the level of muscle performance and fitness of the lower limbs. For the future, researchers need to take into consideration developing longitudinal studies to verify changes in muscular fitness during growth and development. In addition, it is necessary to quantify the levels of physical activity and nutrition in order to diminish interpretation bias. However, in addition to the importance of these results for the Maule Region, these findings can also be generalized to other Chile contexts,because the $\mathrm{HJ}$ is a well-known and widely used worldwide muscular fitness test.
In conclusion, differences emerged in the muscle fitness performance between the students from the Maule Region and those of the international studies. These differences began during childhood until the beginning of adolescence. Later, the values at adulthood approached those of the multi-centric European studies. The proposed percentiles are an easy-to-use tool, and they may be used to classify the strength of the lower limbs of students in relation to health and sports performance. The Maule results on percentiles to evaluate muscular performance are worth to be extended to Chilean students at primary and secondary levels.

\section{List of acronyms}

BMI - Body Mass Index,

HJ - Horizontal jump

SD - standard deviation

$\mathrm{X}$ - Average

WC - waist circumference

\section{Authors contributions}

MCB, FC, WC: critical review of important intellectual content; and final approval of the version to be published; RVE, CUA, FC, FA, JM: data acquisition, analysis and interpretation of data, critical review and final approval of the version to be published; CA: manuscript translation and final approval; JST; data processing, critical review and final approval of the version to be published.

\section{Acknowledgments}

A special acknowledgement of appreciation goes to the team of professionals in the municipal schools of Talca for their collaboration and participation in the data collection.

\section{Funding None}

\section{Conflict of Interest}

The authors declare no competing interests.

\section{Ethical Publication Statement}

We confirm that we have read the Journal's position on issues involved in ethical publication and affirm that this report is consistent with those guidelines.

\section{Corresponding Author}

Marco Antonio Cossio Bolaños, PhD, Av San Miguel s/n Talca, Chile.

ORCID iD: 0000-0001-7230-9996

E-mail: mcossio1972@hotmail.com

E-mails and ORCID iD of co-authors

Rossana Gomez-Campos: rossaunicamp@gmail.com

ORCID iD: 0000-0001-6509-5707

Ruben Vidal-Espinoza: rvidale@gmail.com

ORCID iD: 0000-0002-8593-5248

Luis Felipe Castelli Correia de Campos:

lcastelli@ubiobio.cl

ORCID iD: 0000-0000-0001-7771-6486 
Cynthia Lee Andruske: candruske@gmail.com ORCID iD: 0000-0000-0001-7762-0310

Jose Sulla-Torres: jsulla@unsa.edu.pe ORCID iD: 0000-0000-0001-5129-430X

Camilo Urra-Albornoz: c.urra.albornoz@gmail.com ORCID iD: 0000-0000-0002-5936-359X

Wilbert Cossio-Bolaños: wilbert dam@yahoo.com

ORCID iD: 0000-0000-0002-5519-1911

Fernando Alvear-Vasquez: fernandoalvearvasquez@gmail.com

ORCID iD: 0000-0000-0002-9461-1384

Jorge Mendez-Cornejo: jmendez@ucm.cl ORCID iD: 0000-0000-0002-3925-170X

\section{References}

1. Fernandez-Santos JR, Gonzalez-Montesinos JL, Ruiz JR, Jiménez-Pavón D, Castro-Piñero J. Kinematic analysis of the standing long jump in children 6-to 12-years-old. Measurement in Physical Education and Exercise Science 2018; 22(1); 70-78. doi: 10.1080/1091367X.2017.138 3913

2. Council of Europe Committee for the Development of Sport. EUROFIT. Handbook for the EUROFIT Tests of Physical Fitness. Strasbourg, France: Council of Europe, 1993.

3. Canadian Society for Exercise Physiology (CSEP). The Canadian Physical Activity, Fitness \& Lifestyle Approach (CPAFLA): CSEPHealth \& Fitness Program's Health-Related Appraisal and Counselling Strategy. Ottawa, Canada, 2003.

4. Artero EG, España-Romero V, Castro-Piñero J, Ruiz J, Jiménez-Pavón D, Aparicio V, Gatto-Cardia M, Baena P, Vicente-Rodríguez G, Castillo MJ, Ortega FB. Criterion-related validity of field-based muscular fitness tests in youth. J Sports Med Phys Fitness. 2012; 52(3): 263-272.

5. Ortega FB, Ruiz JR, Castillo MJ, Sjöström M. Physical fitness in childhood and adolescence: a powerful marker of health. Int J Obes (Lond) 2008; 32(1): 1-11, 2008. doi:10.1038/ sj.ijo.0803774

6. Cohen D, Gomez-Arbelaez D, Camacho PA, Pinzon S, Hormiga C, Trejos-Suarez J, Duperly J, Lopez-Jaramillo P. Low muscle strength is associated with metabolic risk factors in Colombian children: The ACFIES study. PLoS One 2014; 9(4):e93150, 2014. doi: 10.1371/journal.pone.00 93150.

7. Sepúlveda XC, Méndez JC, Duarte CF, Herrera M, Gómez-Campos R, Lazari E, Cossio-Bolanos M. Relationship between body adiposity and horizontal jump in school children and adolescents. Rev Chil Pediatr. 2018; 89(6): 701-708. doi: 10.4067/S037041062018005001003

8. Granacher U, Lesinski M, Büsch D, Muehlbauer T, Prieske O, Puta C, and Behm DG. Effects of resistance training in youth athletes on muscular fitness and athletic performance: a conceptual model for long-term athlete development. Front Physiol. 2016; 7: 164. doi: 10.3389/fphys. 2016.00164

9. Castro-Piñero J, Ortega FB, Artero EG, GirelaRejón MJ, Mora J, Sjöström M, Ruiz JR. Assessing muscular strength in youth: usefulness of standing long jump as a general index of muscular fitness. J Strength Cond Res. 2010 Jul;24(7):1810-7. doi: 10.1519/JSC.0b013e3181ddb03d.

10. Ramírez-Vélez R, Martínez M, Correa-Bautista JE, Lobelo F, Izquierdo M, Rodríguez-Rodríguez F, Cristi-Montero C. Normative reference of standing long jump for colombian schoolchildren aged 917.9 years: The FUPRECOL Study. J Strength Cond Res. 2017; 31(8):2083-2090. doi: 10.1519/JSC.0000000000001633

11. Hobold E, Pires-Lopes V, Gómez-Campos R, De Arruda M, Andruske CL, Pacheco-Carrillo J, Cossio-Bolaños MA. Reference standards to assess physical fitness of children and adolescents of Brazil: an approach to the students of the Lake Itaipú region-Brazil. PeerJ 2017; 5: e4032. doi: 10.7717/peerj.4032

12. Dobosz J, Mayorga-Vega D, Viciana J. Percentile values of physical fitness levels among polish children aged 7 to 19 years-a population-based study. Cent Eur J Public Health. 2015; Dec;23(4):340-51. doi: 10.21101/cejph. a4153.

13. Saint-Maurice PF, Laurson KR, Kaj M, Csányi T. Establishing normative reference values for standing broad jump among Hungarian youth. Res Q Exerc Sport. 2015; 86(sup1):S37-S44.

14. Tomkinson GR, Carver KD, Atkinson F, Daniell ND, Lewis LK, Fitzgerald JS, Lang JJ, Ortega FB. European normative values for physical fitness in children and adolescents aged 9-17 years: results from 2779165 Eurofit performances representing 30 countries. Br J Sports Med. 2018 Nov;52(22):1445-14563. doi: 10.1136/bjsports2017-098253.

15. Gomez-Campos R, De Arruda M, Hobold E, Abella $\mathrm{CP}$, Camargo $\mathrm{C}$, and Cossio-Bolanos MA. Valoración de la Maduración Biológica: Usos y Aplicaciones en el ámbito Escolar. Revista Andaluza de Medicina del Deporte 2013; 6(4):151160.

16. World Medical Association. World Medical Association Declaration of Helsinki: recommendations guiding medical doctors in biomedical research involving human subjects. France: Ferney-Voltaire, 1989.

17. Ross WD, and Marfell-Jones M.J. Kinanthropometry. Physiological Testing of Elite Athlete; Human Kinetics: Champaign, IL, USA, 1991; pp. 223-308.

18. Konstantinos D. Tambalis, Demosthenes B. Panagiotakos, Glykeria Psarra, Stelios Daskalakis, Stavros A. Kavouras, Nickos Geladas, Tokmakidis 
S, Sidossis LS. Physical fitness normative values for 6-18-year-old Greek boys and girls, using the empirical distribution and the lambda, mu, and sigma statistical method. Eur J Sport Sci. 2016; 16:6:736-746. doi: 10.1080/17461391.2015 .1088577

19. Cole TJ, Bellizzi MC, Flegal KM, Dietz WH. Establishing a standard definition for child overweight and obesity worldwide: international survey. Bmj 2000; 320(7244):1240. doi: 10.1136/bmj.320.7244.1240.

20. Tambalis KD, Panagiotakos DB, Psarra G, Daskalakis S, Kavouras SA, Geladas N, Tokmakidis S, Sidossis LS. Physical fitness normative values for 6-18-year-old Greek boys and girls, using the empirical distribution and the lambda, mu, and sigma statistical method. Eur J Sport Sci. 2016; 16(6):736-746. doi: 10.1080/17461391.2015.1088577

21. Gabbett TJ. Physiological and anthropometric characteristics of starters and non-starters in junior rugby league players, aged 13-17 years. J Sports Med Phys Fitness. 2009; 49(3): 233-39.

22. Chung LMY, Chow LPY, Chung JWY. Normative reference of standing long jump indicates gender difference in lower muscular strength of pubertal growth. Health 2013; 5: 6-11. doi: 10.4236/health.2013.56A3002.

23. Fan HB. Optimization Research on Measurement and Evaluation System of strength quality of ShangHai 6-14 Years old Students [Ph.D.thesis], East China Normal University, 2017.

24. Fry AC, Kraemer WJ. Physical performance characteristics of American collegiate football players. J Strength Cond Res. 1991; 5(3): 126-138.

25. Przeweda R, Dobosz J. Growth and physical fitness of Polish youths in two successive decades. J Sports Med Phys Fitness. 2003; 43(4): 465.

26. Bergier J, Kapka-Skrzypczak L, Bilinski P, Paprzycki P, Wojtyla A. Physical activity of Polish adolescents and young adults according to IPAQ: a population based study. Ann Agric Environ Med.2012; 19(1): 109-115

27. Sygit K, Kollataj W, Gozdziewska M, Sygit M, Kollataj B, Karwat ID. Lifestyle as an important factor in control of overweight and obesity among schoolchildren from the rural environment. Ann Agric Environ Med. 2012; 19(3).
28. Yang YJ. An Overview of Current Physical Activity Recommendations in Primary Care. Korean J Fam Med 2019; 40(3):135-142. https://doi.org/10.4082/kjfm.19.0038

29. Ruiz JR, Ortega FB, Gutierrez A, Meusel D, Sjöström M, Castillo MJ. Health-related fitness assessment in childhood and adolescence: a European approach based on the AVENA, EYHS and HELENA studies. J Public Health. 2006; 14(5): 269-277. doi: 10.1007/s10389-006-0059-z

30. Golle K, Muehlbauer T, Wick D, Granacher U. Physical fitness percentiles of German children aged 9-12 years: findings from a longitudinal study. PLoS One. 2015; 10(11). https://doi.org/10.1371/ journal.pone.0142393

31. Catley MJ, Tomkinson GR. Normative healthrelated fitness values for children: analysis of 85347 test results on 9-17-year-old Australians since 1985. Br J Sports Med. 2013; 47(2): 98-108. doi: 10.1136/bjsports-2011-090218

32. Ortega FB, Artero EG, Ruiz JR, España-Romero V, Jiménez-Pavón D, Vicente-Rodríguez $G$, et al. Physical fitness levels among European adolescents: the HELENA study. Br J Sports Med. 2011; 45(1): 20-29. doi: 10.1136/bjsm.2009.062 679

33. Gómez-Campos R, Andruske CL, De Arruda M, Sulla-Torres J, Pacheco-Carrillo J, Urra-Albornoz C, Cossio-Bolaños M. Normative data for handgrip strength in children and adolescents in the Maule Region, Chile: Evaluation based on chronological and biological age. PloS One 2018;13(8). doi: 10.1371/journal.pone.0201033

34. Honkala S. World Health Organization approaches for surveys of health behaviour among schoolchildren and for health-promoting schools. Med Princ Pract. 2014; 23(Suppl. 1): 24-31.

35. Jakubowski TL, Faigenbaum AD, Lindberg C. Increasing physical activity in children: From evidence to action. MCN Am J Matern Child Nurs. 2015; 40(4): 213-219. doi: 10.1097/NMC.0000000 000000148 .

Submission: November 04, 2020

Revision received: December 27, 2020 Accepted for publication: January 18, 2021 